\title{
The Children Left Behind
}

Sarah A. Gillard, Purdue University North Central, USA

Sharlett Gillard, University of Southern Indiana, USA

\begin{abstract}
This article explores some of the deficits in our educational system in regard to non-hearing students. It has become agonizingly clear that non-hearing students are being left out of the gallant sweep to enrich our children's educations. The big five areas of literacy, at best, present unique challenges for non-hearing students and, in some cases, the challenges are insurmountable. These children need advocates not only to help them succeed, but also to heighten awareness of their struggle so that future generations may be aided by the studies of today.
\end{abstract}

Keywords: Non-Hearing Students; Standards; Deaf Students; Children Left Behind; No Child Left Behind

\section{INTRODUCTION}

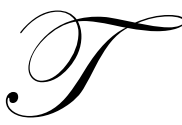

here are deficits in our educational system in regard to non-hearing students. It has become agonizingly clear that non-hearing students are being left out of the gallant sweep to enrich our children's educations. These deaf students are falling through the cracks of our educational system and many educators and government officials are not even aware that there is a problem.

Deaf students do not have the same opportunities that children of the hearing world possess. For example, many standards listed in the Common Core State Standards for English Language Arts pertain only to those students that can hear, vocalize, and sound out words. These standards for the state of Indiana cannot pertain to deaf students. Consequently, if a teacher needs or wishes to have these standards for deaf students, the teacher is compelled to create and/or modify standards, perhaps by modifying those that the government put into place to fit the needs and capabilities of non-hearing students.

The National Reading Panel Report (National Institute of Child Health and Human Development [NICHD], 2000) summarized several decades of scientific research that clearly shows that effective reading instruction addresses five critical areas: 1) phonemic awareness, 2) phonics, 3) fluency, 4) comprehension, and 5) vocabulary. These five areas were incorporated into the No Child Left Behind Act and the Reading First initiative as essential components of effective reading instruction. The implication and impact of these initiatives for non-hearing children is profound.

\section{THE BIG FIVE AREAS OF LITERACY AND THE NON-HEARING STUDENT}

The innate ability of non-hearing students dramatically alters the effects of the Big Five areas of literacy. Each component of the Big Five presents unique challenges for non-hearing children, and some of those challenges are insurmountable.

\section{Phonemic Awareness}

Phonemic awareness is the ability of a student to recognize that words are made up of a certain set of sounds. This is not possible for non-hearing students as they are unable to hear the sounds that the words make.

Phonemes are the basic building blocks of the spoken word. They may occur in the beginning, middle, or end of a word. For example, the phoneme /b/ occurs in the beginning of "ball," the middle of "rabbit," and the end of "grab." While a hearing student would be able to identify the location of the phoneme /b/ when asked, a nonhearing student would find the task impossible. 


\section{Phonics}

Phonics is a slightly easier concept for a deaf student to grasp. Phonics helps a reader learn to decode letters into sounds or words. A good reader is able to sound out words when presented with an unknown word. However, an issue arises when the reader is non-hearing. How are students supposed to sound out unknown words if they cannot hear? While the "sounding out" strategy is not available as a means of decoding words for non-hearing students, they are still able to memorize that certain letters, when put together, will form certain words.

The grapheme-phoneme relationship between letters and sounds work together to make words in the written and spoken realms. While it is possible for non-hearing students to memorize that certain letters go together to make words, without proper guidance, these children will have very poor decoding skills.

\section{Fluency}

Sebastian Wren states that "a person's ability to read and comprehend text at high levels depends upon that person's ability to comprehend language at high levels, as well as that person's ability to decode written text into a comprehensible linguistic form with adequate ease and fluency."

There are five basic steps a student must work through in order to decode a word. The student must recognize the letters in a word, associate each letter with its sound, hold the sounds in sequence in memory, blend the sounds together to determine the word, and finally, retrieve the meaning of the word.

To be able to decode, students must be knowledgeable of the letter-sound relationships and of letter patterns to correctly pronounce words. This becomes quite difficult for non-hearing students. Instead of being able to sound out words aloud, non-hearing students are forced to memorize words and letter patterns in hopes of becoming a more fluent reader.

Studies have shown that when children do not have to do the decoding on their own while reading texts, their comprehension of the material being read increases dramatically (Bertelson, 1986). This line of thought shows that non-hearing students may be profoundly reading impaired by their lack of literacy decoding skills.

\section{Comprehension}

Comprehension, for the deaf student, is comparatively easier than the three previously reviewed elements of literacy, but still has significant challenges. While a deaf student may be able to read a story and comprehend most of it, the scaffolding for complete comprehension is unavailable. If a story, for instance, is about the sounds of the wildlife in a forest, the student will be able to understand that the author is in a forest, with animals, listening. He will not fully be able to understand or grasp the concepts that the animals are making sounds, what those sounds might be, or how those sounds will affect the author. It is not at all part of the scaffolding of a deaf person. The only exceptions to this would be if the student went deaf after they were older and already had auditory experiences.

\section{Vocabulary}

The lexicon, or the collection of words that every speaker of the language uses, is a student's internalized vocabulary. The number of words a person has in his or her vocabulary directly correlates to the time that he or she spends reading (Hayes and Ahrens, 1988).

Five to six year old students have a working vocabulary of 2,500-5,000 words. Depending on the student's literacy skills when he or she enters the first grade, the student will lean toward the top or the bottom of the range (Graves, 1986). The literacy skills of a non-hearing child will be considerably less developed than those of a hearing child, all other factors being equal. The non-hearing child will therefore be at a disadvantage as compared to a hearing child. 
According to White, Graves and Slater (1990), by the first grade, the vocabulary of a disadvantaged student is half that of an advantaged student; and the gap widens over time because the vocabulary growth is slower for disadvantaged students than for advantaged students.

This phenomenon has been labeled the "Matthew Effect" (Walberg and Tsai, 1983). Its name came from Matthew's Gospel that says, "For unto every one that hath shall be given, and he shall have abundance: but from him that hath not shall be taken away even that which he hath" (Matthew 25:29). This passage can be summarized as, "the rich get richer and poor get poorer." Without intervention, some students quickly develop and build upon strong literacy foundations on their own, while other students languish behind their more fortunate peers (Wren, 2006).

Without the strong literacy foundation of American Sign Language (ASL) or English at home, the nonhearing students that are entering Kindergarten will not be able to step into the academic setting and be successful without outside intervention from the educator.

\section{ASSESSMENT OF NON-HEARING STUDENTS}

Assessment of deaf students also becomes a challenge. When "orally" testing these students, obviously they must be tested using sign language. The iconicity of several words in ASL questions the validity of standardized test scores. When a student is asked, for example, what to do with a hat, the sign for hat is a motion of placing a hat on one's head. When the question is posed in ASL, the student will have been given a clue as to the function of the hat just from the highly iconic sign for the word "hat."

The question has been posed to the fairness of signing questions to deaf students. While studies have shown a slight increase in some responses to questions that have highly iconic words, for the most part, standardized test scores do not seem to be swayed by the iconicity of the questions when posed in American Sign Language (Markham, 2004).

\section{ADDITIONAL ACADEMIC BARRIERS FOR NON-HEARING STUDENTS}

Children that are deaf are at an academic disadvantage from the start of their schooling (Strong, 1997). Since ASL has no written form, students must not only learn a second language when learning English, they must do so while also gaining an understanding of the complexities of written English. Studies have found that non-hearing children do better in an academic setting if they have been introduced to American Sign Language from birth (Cummins, 2004). Whether their parents were hearing or non-hearing, they are much more likely to understand the complexities of another language if they have a native language first (Strong, 1997).

Sadly, many non-hearing children are taught no language from birth, due to either parental ignorance or negligence. Many of these parents are not sure what they should do with their child, especially a non-hearing child born into a hearing family. Often the only true language that these children learn is introduced upon commencement of Kindergarten. By this time, children may learn ASL and English, but most will never be fully fluent in either. Most non-hearing students graduate with no higher than a fourth grade reading level, and only seven percent of nonhearing students obtain a seventh grade or higher reading level (Strong, 1997).

Non-hearing children that are taught ASL from birth or early childhood do much better in the academic venue. Since their native language is American Sign Language, they understand the complexities that any language will have when it comes to grammatical rules. This cognitive scaffolding is useful as the non-hearing student learns English. Studies have shown that deaf children that have ASL as a native language are also able to become fluent in English or other languages much easier than those children that do not (Cummins, 2004).

Studies have found that students are able to transfer knowledge of one language to a second language quite easily. Once the brain has learned how to decode the first language, the second is easier for the cognitive functions of the brain to compute (Cummins, 2004). There are some opponents to the theory of teaching deaf students first in ASL then slowly inserting English instruction as well, but studies have proven that deaf children do exceedingly better if they know ASL before learning English. By learning a second language, the student becomes more 
proficient in the first language. By learning the grammatical rules and nuances of the second language, the student is then able to take a new look at the native language and better understand its grammatical rules and nuances. The second language actually brings the student to a deeper, more cognitive awareness of his first language.

\section{CONCLUSION}

The listening/speaking areas of the Big Five are impossible for deaf students. Obviously, they are unable to speak with vocal clarity. Listening skills are insurmountable as well. Of the Big Five areas, the easiest for nonhearing students is vocabulary, or understanding the meanings of words. That is a concept that deaf students are able to grasp; although, there may be a problem with the comprehension of some words due to the aforementioned lack of scaffolding.

Non-hearing students' written work may suffer as a result of several factors, including, but not limited to, spelling and grammar. Both are difficult. Since words are unable to be sounded out, spelling words have to be memorized as site words only; and the complexity of the grammatical rules can be overwhelming. In American Sign Language (ASL), the grammar rules are totally different than in English, so when the student tries to write in English, using the grammatical rules of ASL, the sentences come out garbled and nonsensical.

The deaf culture is a forgotten spectrum of education. These children need advocates not only to help them succeed, but also to heighten awareness of their struggle so that future generations may be aided by the studies of today.

\section{AUTHOR INFORMATION}

Sarah A. Gillard is a researcher at Purdue University North Central. She earned her Master's in Elementary Education and is pursuing a doctoral degree in Educational Psychology. Sarah is particularly interested in the pedagogical skills teachers use to reach non-hearing learners. Being a Sign Language instructor, she has witnessed first-hand the academic struggles of the non-hearing learner. E-mail: s.gillard@ hotmail.com

Sharlett Gillard is a Professor of Computer Information Systems at the University of Southern Indiana. Throughout her career she has been interested in numerous, diverse education issues at all levels of the teaching/learning experience, which has led to collaboration with professionals in various disciplines. E-mail: sgillard@usi.edu. Corresponding author.

\section{REFERENCES}

1. $\quad$ Bertelson, P. (1986). The onset of literacy: Liminal remarks. Cognition. Vol 24 (1-2), 1-30.

2. Beluggi, U. and Studdert-Kennedy, M. Eds. (1980). Signed and Spoken Language: Biological constraints on linguistic form. Deerfield Beach, FL: Verlag Chemie.

3. Cummins, Jim (2004).The relationship between American Sign Language proficiency and English academic development: a review of the research. ASL Think Tank, 1-18.

4. Graves, M.F. (1986). Vocabulary learning and instruction. In E.Z. Rothkopf (Ed.), Review of Research in Education, 13, 49-89.

5. Hayes, D.P. and Ahrens, M.G. (1988). Vocabulary simplification for children: A Special case of "motherese"? Journal of Child Language, 15(2), 395-410.

6. Markham, Paula T. \& Elaine M. Justice (2004). Sign language iconicity and its influence on the ability to describe the function of objects. Journal of Communication Disorders, 37:6, 535-546.

7. National Institute of Child Health and Human Development. (2000). Report of the National Reading Panel. Teaching children to read: An evidence-based assessment of the scientific research literature on reading and its implications for reading instruction: Reports of the subgroups (NIH Publication No. 00-4754). Washington, DC: U.S. Government Printing Office.

8. Strong, Michael \& Prinz, Philip M. (1997). A study of the relationship between American Sign Language and English literacy. Journal of Deaf Studies and Deaf Education, 2:1, 37-46. 
9. White, T. G., Graves, M. F., and Slater, W. H. (1990). Growth of reading vocabulary in diverse elementary schools: Decoding and word meaning. Journal of Educational Psychology, 82 (2), 281-290.

10. Wren, S. (2006). The Reading Assessment Database for Grades K-2. Southwest Educational Development Laboratory, Austin TX. http://www.sedl.org/reading/rad 
NOTES 